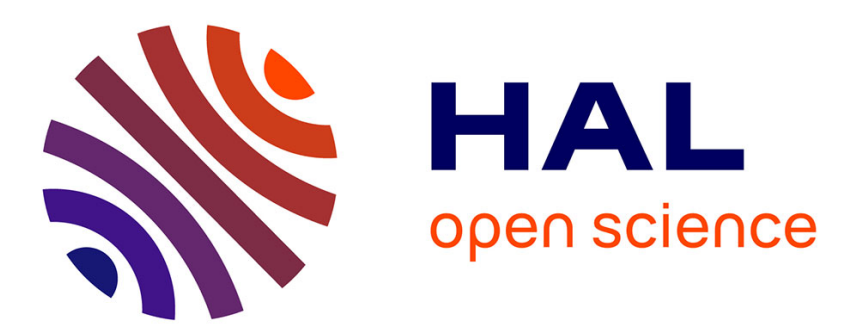

\title{
Influence of citric acid on thermoplastic wheat flour/poly (lactic acid) blends. II. Barrier properties and water vapor sorption isotherms
}

Houssein Abdillahi, Elodie Chabrat, Antoine Rouilly, Luc Rigal

\section{- To cite this version:}

Houssein Abdillahi, Elodie Chabrat, Antoine Rouilly, Luc Rigal. Influence of citric acid on thermoplastic wheat flour/poly (lactic acid) blends. II. Barrier properties and water vapor sorption isotherms. Industrial Crops and Products, 2013, vol. 50, pp. 104-111. 10.1016/j.indcrop.2013.06.028 . hal00865756

\section{HAL Id: hal-00865756 https://hal.science/hal-00865756}

Submitted on 25 Sep 2013

HAL is a multi-disciplinary open access archive for the deposit and dissemination of scientific research documents, whether they are published or not. The documents may come from teaching and research institutions in France or abroad, or from public or private research centers.
L'archive ouverte pluridisciplinaire HAL, est destinée au dépôt et à la diffusion de documents scientifiques de niveau recherche, publiés ou non, émanant des établissements d'enseignement et de recherche français ou étrangers, des laboratoires publics ou privés. 


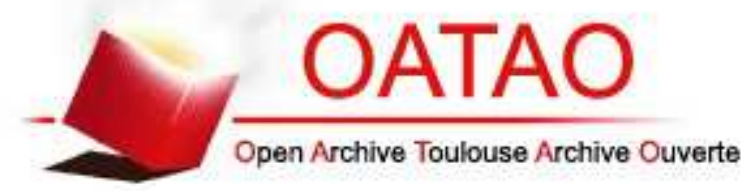

\section{Open Archive TOULOUSE Archive Ouverte (OATAO)}

OATAO is an open access repository that collects the work of Toulouse researchers and makes it freely available over the web where possible.

This is an author-deposited version published in : http://oatao.univ-toulouse.fr/ Eprints ID : 9550

To link to this article : DOI:10.1016/j.indcrop.2013.06.028

URL : http://dx.doi.org/10.1016/j.indcrop.2013.06.028

To cite this version : Abdillahi, Houssein and Chabrat, Elodie and Rouilly, Antoine and Rigal, Luc. Influence of citric acid on thermoplastic wheat flour/poly (lactic acid) blends. II. Barrier properties and water vapor sorption isotherms. (2013) Industrial Crops and Products, vol. 50 . pp. 104-111. ISSN 0926-6690

Any correspondance concerning this service should be sent to the repository administrator: staff-oatao@ listes-diff.inp-toulouse.fr 


\title{
Influence of citric acid on thermoplastic wheat flour/poly(lactic acid) blends. II. Barrier properties and water vapor sorption isotherms
}

\author{
H. Abdillahi ${ }^{\mathrm{a}, \mathrm{b}, *}$, E. Chabrat ${ }^{\mathrm{a}, \mathrm{b}}$, A. Rouilly ${ }^{\mathrm{a}, \mathrm{b}}$, L. Rigal ${ }^{\mathrm{a}, \mathrm{b}}$ \\ a Université de Toulouse, INPT, LCA (Laboratoire de Chimie Agro-industrielle), ENSIACET, 4 Allée Emile Monso, BP 44362, 31030 Toulouse Cedex 4, France \\ ${ }^{\mathrm{b}}$ INRA, LCA (Laboratoire de Chimie Agro-industrielle), France
}

\begin{abstract}
A B S T R A C T
The effects of citric acid on wheat flour/glycerol/poly(lactic) acid (PLA) blends prepared by one-step twinscrew extrusion have been studied to improve barrier properties of starch based materials. A series of injected samples were produced from prepared compounds with varying ratio ( $0-20$ part) of citric acid. The effects of citric acid on the water vapor permeability, oxygen permeability and water solubility in the film were then investigated. The barrier properties results proved that citric acid behaves as compatibilizing agent between starch and PLA phases for ratios between 0 and 10 parts. When the added amount
\end{abstract}

Keywords:

Citric acid

Starch

Wheat flour

Poly(lactic acid)

Extrusion

Barrier properties

Sorption isotherms

\section{Introduction}

Bioplastics are topical and their use is becoming more abundant in recent years. Researchers focusing their works on the processing of these materials since sustainable policies tend to expand with the decreasing reserve of fossil fuels and the growing concern for the environment. Replacement of conventional plastics by degradable polymers, particularly for short-lived applications such as packaging, catering, surgery is of major interest for different actors of the socio-economical life.

In packaging applications, agro-polymers from agroressources (starch, cellulose, protein, etc.) represent a new alternative to the ubiquitous of synthetic polymers (polyethylene terephtalate, polyvinyl chloride, polystyrene, etc.). These agro-materials represent a strong and emerging answer to develop novel materials labeled "environmentally friendly".

Abbreviations: WF, wheat flour; PLA, poly(lactic acid); TPS, thermoplastic starch WVP, water vapour permeability; $\beta$, solubility coefficient (hydrophilicity, adsorptivity); X, equilibrium moisture content; DMTA, dynamic mechanical and thermal analysis; FTIR, Fourier Transform Infrared Spectroscopy; SEM, Scanning Electronic Microscopy.

* Corresponding author at: Laboratoire de Chimie Agro industrielle, 4 Allée Emile Monso, BP 44362, 31030 Toulouse, France. Tel. +33 0534323511 fax: +330534323598

E-mail address: abdillahi.houssein@yahoo.fr (H. Abdillahi).
Therefore, it appears interesting to use raw materials from cereal product for their immense potential, low price and abundant availability, especially wheat flour that mainly contains starch and protein (Chanvrier et al., 2007; Leblanc et al., 2008). Starch is a natural polysaccharide produced by many plants, as a storage polymer. It's the major carbohydrates reserve in plant tubers and seed endosperm where it's found as granules (Buléon et al., 1998). It has received considerable attention during the last decades as a biodegradable thermoplastic polymer and is probably the most promising materials among naturally biodegradable polymer using renewable resources. Nevertheless, native starch can not be processed as a thermoplastic material because of the strong intramolecular and intermolecular hydrogen. It can be converted into a continuous polymeric entangled phase by mixing with enough water and nonaqueous plasticizer, generally polyols, such as glycerol (Angellier et al., 2006; Forssell et al., 1997; Ghiasi et al., 1982; Liu et al., 2001).

The starch extraction from wheat flour generates a significant additional cost. Thus, to become fully competitive with conventional plastics, it seemed necessary to use wheat flour as thermoplastic materials. The resulting materials can be manufactured using technology already developed for the production of synthetic plastics. However, its hydrophilic nature makes it very sensitive to moisture attack. Thus, it's difficult to reach the same characteristics (dimensional stability, barriers and mechanical properties) than polymers derived from fossil resources, most frequently used in food packaging. 
To improve barrier properties of plasticized wheat flour, poly(lactic) acid (PLA), known for its good barrier properties was used to obtain thermoplastic wheat flour/PLA blends. Similar values of water vapour permeability (WVP) for PLA and synthetic polymers like PET and PS were reported in the literature (Auras et al., 2005) and WVP of PLA did not vary significantly with changes in RH. The authors also reported a decrease in WVP of PLA with increasing temperature, opposite behavior to that of most petroleum-based polymers that exhibit lower water vapour barrier properties at higher temperatures. The values of permeability for $\mathrm{O}_{2}$ of PLA have been shown to be comparable to those of equivalent of conventional materials such as PE and PS (Petersen et al., 1999, 2001).

Blending wheat flour (WF) with PLA is one of the most promising and original approaches because $W F$ is an abundant and cheap resource and PLA has good mechanical and barriers properties. To the best of our knowledge, there is no study concerning WF/PLA blends although several authors (Muller et al., 2012; Yew et al., 2009) have reported the barrier properties of thermoplastic starch/PLA blends.

However hydrophilic starch, with plenty of hydroxyl groups and hydrophobic PLA, with hydroxyl and carboxyl end groups present a poor interfacial adhesion (Almenar and Auras, 2010; Martin and Avérous, 2001). Indeed, starch remains in separate conglomerate form in a PLA matrix. Moreover, the great moisture sensitivity of starch is a disadvantage. Ke and Sun (2001) have reported that PLA/starch blends containing gelatinized starch had greater water absorption than the other blends because the gelatinized starch is more sensitive to water than the granular state. To overcome these shortcomings, certain nontoxic functional additives are required to improve the mechanical, barriers properties and water resistibility of the PLA/starch films.

Several authors (Ghanbarzadeh et al., 2011; Ma et al., 2008; Shi et al., 2007; Thiebaud et al., 1997) have reported that citric acid (CA) may improve the water resistance due to reducing available hydroxyl groups of starch. It has also reported that the primary function of films prepared with lipids was blocking moisture transport due to the high hydrophobicity and decrease the water vapor permeability of biopolymeric films (Gontard et al., 1994). It was found that citrate starch does not swell and gelatinize in hot water as a result of cross-linking reaction (Xie and Liu, 2004). Furthermore, citric acid addition to wheat flour caused to significantly decrease the cross-linking degree of the protein network during extrusion (Gómez-Martínez et al., 2009). CA can also act as a plasticizer and has been shown to promote starch hydrolysis by lowering the $\mathrm{pH}$ (Hirashima et al., 2004; Shi et al., 2007). Citrate esters can be effective in reducing the glass transition temperature and increase the plasticization of TPS and PLA (Labrecque et al., 1997; Shi et al., 2007).

Plasticizers as polyols can affect the water vapor properties of packaging films (Müller et al., 2008). Study of hydration of plasticized starch has shown that interactions between the components of the system formed by starch, plasticizer and water was significantly dependent on the relative humidity to which theses materials were exposed (Godbillot et al., 2006).

Several authors have investigated the behavior of water vapor permeability and the simultaneous behaviors of water diffusivity and solubility in a polymeric matrix (Miller and Krochta, 1997; Sothornvit and Krochta, 2001; Larotonda et al., 2005; Maria Martelli et al., 2006; Rocha Plácido Moore et al., 2006) and few recent studies were found in the literatures regarding the relative influences of these parameters on the water vapor permeability of starch films (Müller et al., 2009; Muller et al., 2012).

In the present paper, citric acid known as nutritionally harmless compared to other substances used for starch derivatization (Xie and Liu, 2004), was used as an additive on wheat flour/glycerol/PLA blends in an industrial-size-twin-screw extruder. A series of molded samples were produced from prepared compounds to assess their suitability for use as packaging materials. The present paper follows an article already reported by Chabrat et al. (2012) who investigated how the addition of citric acid on wheat flour/PLA blends influences films' thermal, morphological and mechanical properties. In this paper, wheat flour/PLA/citric acid blends have been successfully produced on industrial equipments and citric acid has improved the PLA repartition in the matrix and its effects of both compatibilization and plasticization were seen on the mechanical properties. This second part investigates the barrier properties (WVP and $\mathrm{O}_{2}$ permeability) and water vapor sorption isotherms of the blends produced without additional water to conclude on the effects of citric acid on WF/PLA interactions and evaluate the possible use of these compounds as packaging materials.

\section{Experimental}

\subsection{Materials}

Wheat flour was supplied by Gers Farine (France). It is mainly made up of starch (65\%). Secondary components were water (13\%), proteins $(13 \%)$, fibers, essentially hemicelluloses $(2 \%)$ and lipids (1\%). Poly(lactic) acid (PLA) is an extrusion grade and was kindly provided by Natureworks LLC (USA). Its melting temperature was $140^{\circ} \mathrm{C}$. Glycerol (purity $99 \%$ ) was used as starch plasticizer and was supplied by Gaches Chimie (France). Citric acid was obtained from Sigma-Aldrich (France).

\subsection{Thermoplastic starch/PLA blends extrusion}

In this study, five different blends were extruded in an industrial-size twin-screw extruder (Evolum HT53, Clextral (France) with $\mathrm{L} / \mathrm{D}=36$ ). It was equipped with nine modular barrels, each $212.6 \mathrm{~mm}$ long. A cylindrical die with 6 holes was fixed at the end of the extruder. The screw rotational speed was fixed at $250 \mathrm{rpm}$ and temperature profile in the nine barrel sections from feed to die were set of $60-140^{\circ} \mathrm{C}$ for all the experiments (Fig. 1). The screw profile was divided in two main zones, a plasticization zone composed of kneading elements and reverse screw elements in the first half of the barrel and a mixing zone composed of kneading elements in the second half of the barrel. PLA was introduced at the beginning of the second zone, i.e. after starch plasticization. The compositions of the blends can be understood from their names. First, wheat flour (extruded at its equilibrium humidity (13\%)), PLA and glycerol ratio were kept constant at 75 parts, 25 parts and 15 parts respectively. The only variables were citric acid. The generic name for the formulations is CAx with $x$ indicating the concentration of citric acid, with values between 0 and 20 parts.

\subsection{Injection-molding}

After stabilization at $60 \% \mathrm{RH}$ and $25^{\circ} \mathrm{C}$ during three weeks, the plastics pellets were injection-molded into disk-shaped specimens using a Negri Bossi VE160-720 injection molding machine (Italy). Molding temperature profile was defined as following: $80 / 125 / 130 / 145^{\circ} \mathrm{C}$ and backpressure was 10 bar. The holding pressure was 800 bar during $0.5 \mathrm{~s}$ and 600 bar during $0.5 \mathrm{~s}$.

\subsection{Moisture, thickness and density}

Before any film properties determination, samples were conditioned at $25^{\circ} \mathrm{C}$ and $60 \% \mathrm{RH}$ for at least 20 days to stabilize them. The plastics pellets and injection-molded specimens' moisture were determined in triplicates by gravimetric method, after drying at $105^{\circ} \mathrm{C}$ for $24 \mathrm{~h}$ and expressed in g water/100 g dry mass. The thickness of the samples was measured $( \pm 0.01 \mathrm{~mm})$ using a 


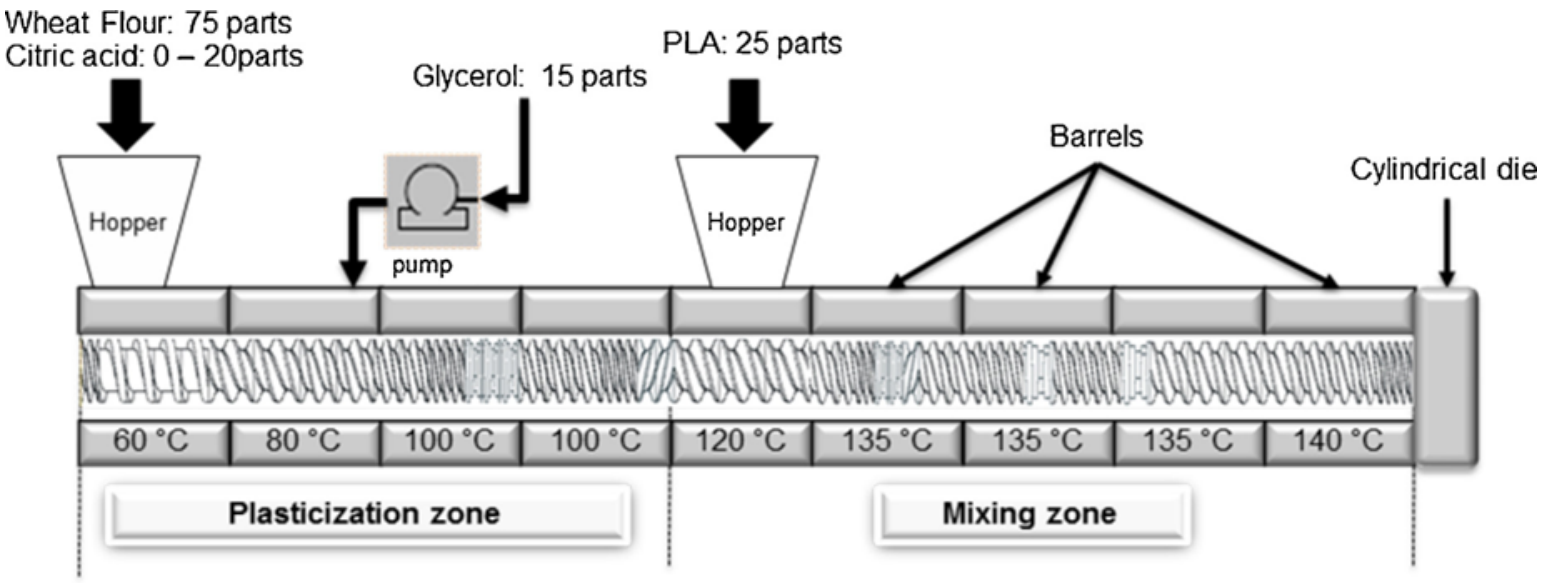

Fig. 1. Industrial-size twin-screw extruder (Evolum HT53, Clextral (France)).

digital caliper micrometer at 5 random positions on the film. In order to determine films density, a hydrostatic balance (Sartorius YDK 01-0D) which enables to weigh a solid in air as well as while suspended in a liquid of known density was used. The film densities were determined with a density determination kit using the Archimedes' principle. In this method, cyclohexane was used as the liquid causing buoyancy. The density of the solid sample is computed from the weight in air divided by its volume. This volume is equal to the loss of weight of the sample divided by the density of the liquid at the temperature of observation. Density of films was calculated using Eq. (1):

$\rho=\frac{W(a) \cdot[\rho(f l)-\rho(a)]}{0.99983[W(a)-W(f l))]}+\rho(a)$

where $\rho$ is the density of the solid, $\rho(f l)$ the density of the liquid, $\rho(a)$ the density of air under standard conditions, $W(a)$ the weight of the solid in air, $W(f l)$ the weight of the solid in liquid. To take account of factors which may affect the density measurements such as volatility of cyclohexane, at least five replicates of each film type were tested.

\subsection{Water sorption isotherms}

A dynamic vapor sorption (DVS Advantage, SMS, Alperton, UK) technique was used to measure water sorption isotherms. DVS is a gravimetric technique which consists of maintaining a sample in a temperature and humidity-controlled chamber to measure the mass variation of the sample when varying the water vapor concentration surrounding it. At the heart of the DVS system is an ultra-sensitive recording microbalance capable of measuring changes in sample mass lower than 1 part per 10 million. The instrument microbalance and stand is housed inside a temperature-controlled incubator. Prior to being exposed to any vapour, the samples are equilibrated at $0 \% \mathrm{RH}$ to remove any surface adsorbed vapour and to establish a dry mass baseline. Samples, typically of 10-12 mg were submitted to the continuous gas flow containing pure nitrogen regulated at a constant pressure between 1 and 2 bar and water vapor saturated in proportion corresponding to the desired relative humidity. The relative humidity is increased step by step during moisture absorption. At each step, the sample mass is allowed to reach equilibrium before humidity is varied. The water uptakes of the samples were determined by measuring mass variation with an accurate microbalance system (DVS, surface measurements systems).
The Guggenheim-Anderson-de Boer (GAB) model was used to fit experimental data of blends sorption isotherms given in Eq. (2):

$X=\frac{C k X_{0} a_{w}}{\left[\left(1-k a_{w}\right)\left(1-k a_{w}+C k a_{w}\right]\right.}$

where $X$ is the equilibrium moisture content on a dry weight basis $(\% \mathrm{w} / \mathrm{w})$ at the water activity $a_{w}(\mathrm{RH} / 100), X_{0}$ is the monolayer moisture content, $C$ the Guggenheim constant related to the first layer heat sorption and $k$ the constant related to the total multilayer heat sorption. All tests were performed twice.

The fit of the experimental model of GAB was performed using Minitab 16 software (State College, USA) using the program of the non-linear regression and quasi-Newton technique. The quality of the model fit was assessed by examining the distribution of the experimental points from the curves of models and the squared deviations. The fitting quality was checked by determining the mean of the square root of the error $\left(R^{2}\right)$.

\subsection{Water solubility coefficient}

The solubility coefficient, also called hydrophilicity or adsorptivity (Larotonda et al., 2005; Rocha Plácido Moore et al., 2006) is a film property that indicates the water gain by $1 \mathrm{~g}$ of dry matter, when the partial pressure of water vapor in the surrounding air increased by $1 \mathrm{~Pa}$. It can be determined by the derivation of GAB model as proposed by Larotonda et al. (2005) using Eq. (3):

$$
\begin{aligned}
\beta= & C k X_{0} a_{w} \times\left[\frac{1}{\left(1-k a_{w}\right)\left(1-k a_{w}+C k a_{w}\right)}\right. \\
& -\frac{a_{w}}{\left[\left(1-k a_{w}\right)\left(1-k a_{w}+C k a_{w}\right)^{2}\right]} \times\left[-k\left(1-k a_{w}+C k a_{w}\right)\right. \\
& \left.\left.+\left(1-k a_{w}\right)(-k+C k)\right]\right]
\end{aligned}
$$

\subsection{Water vapor permeability and effective water diffusion coefficient}

Water vapor permeability (WVP) measurements of the films were performed using the methodology described by ASTM E96/E96M (C16 Committee, 2010). Prior being analyzed, film samples $\left(35 \mathrm{~cm}^{2}\right)$ were conditioned at least for $48 \mathrm{~h}$ at $25^{\circ} \mathrm{C}$ and $60 \%$ relative humidity in a laboratory climatic chamber. Films with $30 \mathrm{~cm}^{2}$ of exposed area were used to hermetically cover cylindrical aluminum cells measuring $6.2 \mathrm{~cm} \times 2.5 \mathrm{~cm}$ (diameter $\times$ depth) and containing $7 \mathrm{mg}$ of anhydrous calcium chloride to maintain the 
Table 1

Moisture, thickness and density of blends reinforced with different content of citric acid.

\begin{tabular}{lccc}
\hline Sample & \multicolumn{2}{l}{ Moisture $\left(\mathrm{g} \mathrm{H}_{2} \mathrm{O} / 100 \mathrm{~g}\right.$ dry matter $)$} & Thickness $(\mathrm{mm})$ \\
\cline { 2 - 4 } & Pellets samples & Injected samples & $1.0 \pm 0.1$ \\
\hline CA0 & $6.24 \pm 0.15^{\mathrm{d}}$ & $6.70 \pm 0.01^{\mathrm{c}}$ & $1.1 \pm 0.02$ \\
CA2 & $7.02 \pm 0.10^{\mathrm{c}}$ & $7.60 \pm 0.03^{\mathrm{b}}$ & $1.0 \pm 0.1$ \\
CA5 & $7.43 \pm 0.05^{\mathrm{b}}$ & $7.61 \pm 0.05^{\mathrm{b}}$ & $1.386 \pm 0.004^{\mathrm{b}}$ \\
CA10 & $7.45 \pm 0.11^{\mathrm{b}}$ & $7.51 \pm 0.17^{\mathrm{b}}$ & $1.377 \pm 0.004^{\mathrm{b}}$ \\
CA20 & $8.20 \pm 0.04^{\mathrm{a}}$ & $8.53 \pm 0.06^{\mathrm{a}}$ & $1.318 \pm 0.007^{\mathrm{d}}$ \\
PLA & $<1$ & $<1$ & $1.0 \pm 0.1$ \\
\hline
\end{tabular}

Different letters in the same column indicate a statistical difference between the mean values $(P<0.05)$.

inside of the cells at $0 \% \mathrm{RH}$. Toric joint seal was used to attach the film to the cell. Test cells were then placed in a climatic chamber, maintained at $25^{\circ} \mathrm{C}$ and $60 \% \mathrm{RH}$. Thereby, difference in partial pressure of water vapor between the inside and the outside of the cell was $1875 \mathrm{~Pa}$. The water vapor then went permeate through the film to restore equilibrium and was progressively fixed by the desiccant which led to an increase of the mass of the measuring cell. Periodical weightings monitored the weight changes. Mass variation was plotted over time. WVP was calculated from the slope $(G)$ of a linear regression of water gain plotted versus time at steady state according to Eq. (4):

$\mathrm{WVP}=\frac{G \cdot \delta}{A \cdot \Delta p}$

where $\delta$ is the film thickness; $A$ is the area of exposed film and $\Delta p$ is the differential water vapor partial pressure across the film. Fick's law and Henry's law were used to calculate film WVP and assume that film solubility and diffusivity are constant. Each test consisted of three replicate measurements.

Larotonda et al. (2005) have established the dependence of the barrier properties (WVP) on the simultaneous effect of water diffusivity in the polymeric matrix $\left(D_{\text {eff }}\right)$ and of the coefficient solubility of water in the film $(\beta)$ according to Eq. (5):

$\mathrm{WVP}=\rho^{s} \cdot \beta \cdot D_{\mathrm{eff}}$

where $\rho^{s}$ is the density of the film $\left(\mathrm{g} / \mathrm{cm}^{3}\right)$.

\subsection{Oxygen permeability}

A Systec Instrument 8001 (Gruter \& Marchand, France) was utilized to measure oxygen transmission rate through blend films according to standard method ASTM D3985 (Ke and Sun, 2001) at atmospheric pressure. Films with $60 \mathrm{~cm}^{2}$ of exposed area were mounted as a sealed semi-barrier between two chambers and exposed to pure nitrogen on one side of the film and pure oxygen on the other. The oxygen that permeates through the film was transported by the nitrogen carrier gas into the oxygen detector (coulometric sensor) and measurements were obtained when steady state was reached. Both gases were set to the desired conditions (temperature and relative humidity). Measurements were performed at $23^{\circ} \mathrm{C}$ and $50 \%$ relative humidity. Conditioning films were used for this experiment.

Oxygen permeability coefficient $\left(\mathrm{cm}^{3} \mathrm{~mm} / \mathrm{m}^{2}\right.$ day) was calculated on the basis of oxygen transmission in the steady state, with the thickness of the films taken into account. Each test consisted of three replicate measurements.

\subsection{Statistical analysis}

Minitab software version 16 was performed to all statistical analysis. Analysis of variance (ANOVA) and the Tukey test for comparison of means were applied to determine the significant differences $(P<0.05)$ among the samples.

\section{Results}

\subsection{Moisture, thickness and density}

Moisture, thickness and density results are presented in Table 1. A slight increase of moisture content of pellet and injected samples as a function of CA content was observed. Whatever form of the blends (pellet or injected), samples containing 20 parts of $C A$ showed higher values of moisture content ( 820 and $853 \mathrm{~g} / 100 \mathrm{~g}$ dry mass for pellet and injected samples respectively). In terms of matter density, significant differences were observed between the samples for all blends. The density of film samples ranged from $1.318 \pm 0.007$ (CA5) to $1.406 \pm 0.003$ (CA20) $\mathrm{g} / \mathrm{cm}^{3}$. Film thickness was constant for all blends $(\sim 1 \mathrm{~mm})$ and was higher compared to those found for conventional materials $(20-100 \mu \mathrm{m})$ such as PE and PS due to the process for obtaining materials (injection-molding) and blends properties.

\subsection{Water sorption isotherms}

The water sorption isotherms of films prepared with different citric acid content at $25^{\circ} \mathrm{C}$ in the water activity range $0<a_{w}<0.9$ are presented in Fig. 2. CA0 has a classical sigmoidal shape that can be described in terms of a three-step moisture absorption (RomanGutierrez et al., 2002). This behavior is typical of water sorption in hydrophilic materials and has also been reported for starch based materials (Godbillot et al., 2006; Mali et al., 2005; Müller et al., 2008). The first part of the sorption curves $\left(a_{w}<0.30\right)$ corresponds to the field of water adsorbed as a monolayer, where polar groups of high binding energy to hydrophilic components (starch, proteins and pentosans) are saturated with water molecules which considered integral parts of the solid phase. During the second stage $\left(0.30<a_{w}<0.6\right)$, additional water molecules are bound onto the monolayer (i.e., multilayer coverage) and water clusters begin to form. During the third step $\left(a_{w}>0.6\right)$, accumulation of water in intermolecular free spaces occurs and results in partial swelling that in turn may expose additional hydrophilic binding sites. The plots obtained for CA2, CA5, CA10 and CA20 were convex to the relative pressure axis. The weak interactions between the water and the films with citric acid (CA2-CA20) led to low uptakes at low relative pressures. However, once a water molecule was become adsorbed at a primary adsorption site, the water-water interactions which were much stronger, were become the driving force of the adsorption process, resulting in accelerated uptakes at higher relative pressure.

Adding 2 part of citric acid to wheat flour/PLA blends decreased its moisture uptake. This decreasing was more pronounced in the water activity range $0<a_{w}<0.45$. The same behavior was observed on the other blends (CA5, CA10 and CA20). In the water activity range $0.3<a_{w}<0.75$, the minimum of water uptake was achieved by a 10 parts of CA addition in the blends. These results are in agreement with previous results reported by Ghanbarzadeh et al. (2011). Therefore, more than $90 \%$ reduction in water absorption 


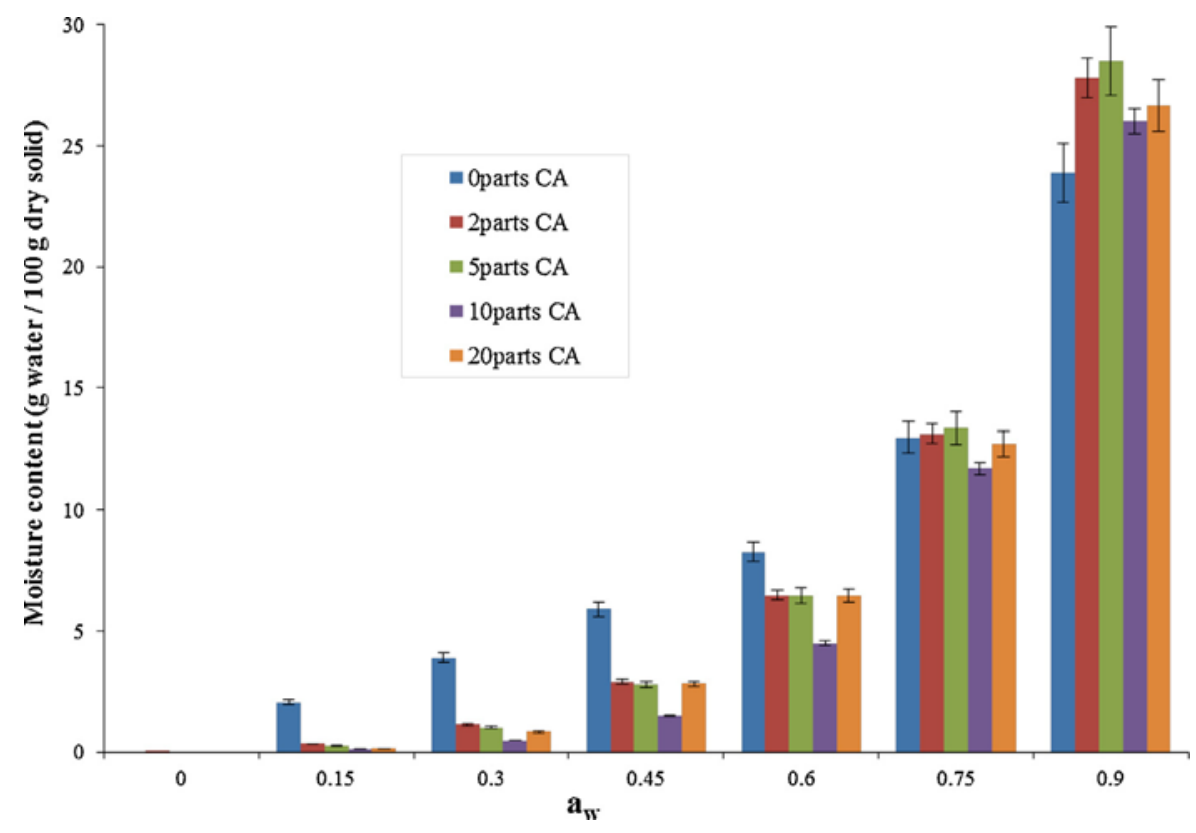

Fig. 2. Sorption isotherms at $25^{\circ} \mathrm{C}$ of wheat flour/PLA/CA blends as a function of $a_{w}$.

was achieved by a 10 parts CA addition at $a_{w}=0.15$ and this reduction was further held to less than $75 \%$ when the water activity was varied from 0.45 to 0.6

The GAB model was used to fit experimental data, showing a remarkable fit over a wide range of $a_{w}$ values. GAB parameters and correlation coefficient which were determined through non linear regression are given in Table 2 . The monolayer water $X_{0}$ indicates the maximum amount of water that can be adsorbed in a single layer per gram of dry film and it is a measure of number sorbing sites (Mali et al., 2005). All samples showed similar values for the monolayer water content $X_{0}$ which are within the range presented for starchy products (Mali et al., 2005; Muller et al., 2012). These results may be related to the similar behavior in terms of their hygroscopicity.

The value for the parameter $C$, relating to the monolayer heat sorption slightly decreased when a low content of CA was added as indicated by the corresponding values obtained for all samples (see Table 2). This might be attributed to weaker water-starch interactions caused by the presence of citric acid which then decreased the amount of bound water molecules. The parameter $k$, related to multilayer sorption heat, was not be affected by citric acid concentration.

\subsection{Water vapor permeability (WVP), solubility coefficient ( $\beta$ ) and effective diffusion coefficient $\left(D_{\text {eff }}\right)$}

The main purpose of food packaging is to protect the content against all kind of deteriorations which can be physical, chemical or microbiological. Depending on the food, packaging should either

Table 2

$\mathrm{GAB}$ parameters for moisture sorption isotherms for blends $\left(R^{2}\right.$ is the correlation coefficient)

\begin{tabular}{llllr}
\hline Sample & \multicolumn{2}{l}{ GAB parameters } & \multirow{2}{*}{$R^{2}$} \\
\cline { 2 - 4 } & $X_{0}$ (g water/g dry solid) & $C$ & $K$ & \\
\hline CA0 & 0.05 & 2.77 & 0.92 & $>0.99$ \\
CA2 & 0.06 & 0.98 & 0.92 & $>0.99$ \\
CA5 & 0.09 & 0.56 & 0.87 & $>0.99$ \\
CA10 & 0.07 & 0.40 & 0.91 & $>0.99$ \\
CA20 & 0.08 & 0.38 & 0.90 & 0.99 \\
\hline
\end{tabular}

completely barrier or at least decrease moisture transfer between food and surrounding atmosphere.

As shown in Table 3, WVP of CAO film ( 0 part of citric acid) was $16.72 \times 10^{-11} \mathrm{~g} \mathrm{~m}^{-1} \mathrm{~s}^{-1} \mathrm{~Pa}^{-1}$ and was the highest WVP value compared to all other blends (CA2-CA20). Water vapor easily went through CAO film, this being due to the immiscibility of wheat starch and PLA and also to the water sensitivity of starch.

The WVP values significantly decreased as soon as 2 parts of CA were added. Films containing 5 and 10 parts showed the lowest WVP values $\left(2.84 \times 10^{-11} \mathrm{~g} \mathrm{~m}^{-1} \mathrm{~s}^{-1} \mathrm{~Pa}^{-1}\right.$ and $3.34 \times 10^{-11} \mathrm{~g} \mathrm{~m}^{-1} \mathrm{~s}^{-1} \mathrm{~Pa}^{-1}$ respectively) and no significant differences were observed between these films according to ANOVA and the Tukey test. However, the WVP values of the blends noticeably increased from $3.32 \times 10^{-11}$ to $14.59 \times 10^{-11} \mathrm{~g} \mathrm{~m}^{-1} \mathrm{~s}^{-1} \mathrm{~Pa}^{-1}$ when increasing the CA content from 10 to 20 parts. The WVP being dependent on the solubility and effective diffusion coefficients, it was of interest to compare their effects on the barrier properties (Table 3 ). Thus, $D_{\text {eff }}$ values had decreased in the presence of citric acid for ratio between 0 and 10 parts from 1.6 to $0.2 \mathrm{~m}^{2} \mathrm{~s}^{-1}$ and then increased again to its initial value.

\subsection{Oxygen permeability}

Analysis of oxygen permeability was performed for injected samples and two commercial films, PS/EVOH/PE and APET for comparison, under similar experimentations conditions, which were

Table 3

Water vapour permeability, solubility and diffusion coefficients of blend films for $a_{w}=0.6$ at $25^{\circ} \mathrm{C}$

\begin{tabular}{lcll}
\hline Sample & $\begin{array}{l}\text { WVP } \times 10^{-11} \\
\left(\mathrm{~g} \mathrm{~m}^{-1} \mathrm{~s}^{-1} \mathrm{~Pa}^{-1}\right)\end{array}$ & $\begin{array}{l}\beta \times 10^{-5} \\
\left(\mathrm{~g} \mathrm{H}_{2} \mathrm{O} / \mathrm{gdry}\right. \\
\text { solid Pa })\end{array}$ & $\begin{array}{l}D_{\text {eff }} \times 10^{-12} \\
\left(\mathrm{~m}^{2} \mathrm{~s}^{-1}\right)\end{array}$ \\
\hline CA0 & $16.72 \pm 2.3^{\mathrm{a}}$ & 7.87 & 1.6 \\
CA2 & $4.94 \pm 0.2^{\mathrm{b}}$ & 7.73 & 0.5 \\
CA5 & $2.84 \pm 0.3^{\mathrm{c}}$ & 8.85 & 0.2 \\
CA10 & $3.34 \pm 0.7^{\mathrm{bc}}$ & 7.33 & 0.4 \\
CA20 & $14.59 \pm 1.6^{\mathrm{a}}$ & 7.72 & 1.4 \\
\hline
\end{tabular}

Different letters in the same column indicate a statistical difference between the mean values $(P<0.05)$. 
Table 4

Oxygen permeability coefficient of the blends at $23^{\circ} \mathrm{C}$ and $50 \%$ RH. Different letters in the same column indicate a statistical difference between the mean values $(P<0.05)$.

\begin{tabular}{ll}
\hline Sample (thickness) & $\begin{array}{l}\mathrm{O}_{2} \text { permeability } \\
\left(\mathrm{cm}^{3} \mathrm{~mm} / \mathrm{m}^{2} \text { day }\right)\end{array}$ \\
\hline CA0 $(1 \mathrm{~mm})$ & $4.77 \pm 0.01^{\mathrm{c}}$ \\
CA2 $(1.1 \mathrm{~mm})$ & $0.31 \pm 0.01^{\mathrm{e}}$ \\
CA5 $(1 \mathrm{~mm})$ & $0.34 \pm 0.02^{\mathrm{e}}$ \\
CA10 $(1 \mathrm{~mm})$ & $1.40 \pm 0.03^{\mathrm{d}}$ \\
CA20 $(1 \mathrm{~mm})$ & $1.23 \pm 0.20^{\mathrm{d}}$ \\
PLA $(1 \mathrm{~mm})$ & $8.66 \pm 0.09^{\mathrm{a}}$ \\
PS/EVOH/PE $(0.5 \mathrm{~mm})$ & $<2 \mathrm{ppm}$ \\
APET $(0.6 \mathrm{~mm})$ & $6.12 \pm 0.18^{\mathrm{b}}$ \\
\hline
\end{tabular}

applied for the blends with citric acid. PS/EVOH/PE is a multilayer film composed of PS (polystyrene) as base material, EVOH (ethylene vinyl alcohol), acting as a barrier, and PE (polyethylene) layer in contact with the packaged product used for packaging meat products, fish, sauces, cheeses, etc. APET (amorphous polyethylene terephtalate) is a thermal plastic with excellent gas, water and chemical barrier properties and compliant for direct food contact. Oxygen permeability measurements were performed at $23^{\circ} \mathrm{C}$ and $50 \%$ relative humidity, which are a standard use condition. The results found for all blend films are presented in Table 4. It's well known that the oxygen barrier of PLA and starch polymers and of the copolyester is similar than for APET and PS/EVOH/PE ( $<2$ ppm, i.e. value is less than apparatus sensitivity) is an excellent gas and moisture barrier films (Auras et al., 2005; Le Corre et al., 2010). The measured oxygen permeability value for PLA was about $8.67 \mathrm{~cm}^{3} \mathrm{~mm} / \mathrm{m}^{2}$ day. The measured permeability value for blends significantly decreased when a low content of citric acid was added ( 2 and 5 parts of CA) and stabilized at a value around $1 \mathrm{~cm}^{3} \mathrm{~mm} / \mathrm{m}^{2}$ day when the added amount of CA exceeds 5 parts (CA10 and CA20). No significant differences were observed for CA2 and CA5.

\section{Discussion}

\subsection{Effect of density on the WVP and $\mathrm{O}_{2}$ permeability}

At low pressure when Fick's law and Henry's law are obeyed, the following equation as is generally accepted should hold:

$P=D \times S$

where $S$ and $D$ are respectively the solubility and diffusion coefficient and $P$ is the permeability coefficient. Gas permeability is due to a "jumping" process whereby a permeant molecule spends most of the time in free volume holes and occasionally jumps into a neighboring hole by formation of a connecting channel. Wonders and Paul (1979) have demonstrated that densification of a glassy polymer shifts sorption isotherms to lower solute concentration; i.e. decreases the apparent solubility coefficient in the dual mode sorption model (Henry's law and Langmuir modes of sorption). Moreover, changes in polymer density should induce the variation of another important property of a material, the cohesion energy density (CED) that is related to the coefficient of diffusion according to the expression suggested by Shishatskii et al. (1996) by combining Arrhenius law and expression suggested by Meares (1954):

$\ln D=\frac{\ln D_{0}-\pi d^{2} N_{0} \lambda C E D}{4 R T}$

with

$\mathrm{CED}=E_{\mathrm{coh}} \times \rho$

where $d$ is the collision diameter of a diffusant molecule, $N_{0}$ is the Avogrado number, $\lambda$ is the jump distance in the activation state and $E_{\text {coh }}$ is the molar cohesion energy. In agreement with these equations, higher density should lead to lower permeability. Nevertheless, densities of wheat flour/PLA/citric acid blends follow same evolution of WVP and oxygen permeability (Tables 1, 3 and 4). This is in contradiction with previous demonstration. The decrease of density for CA5 might be attributed to the decrease of molecular weight as also reported by Chabrat et al. (2012). Indeed, a decrease of blends viscosity which indicates that starch and PLA were hydrolysed was observed in the first part of this study and already reported by another research group (Hirashima et al., 2004).

The increase in the densities for CA10 and CA20 could be attributed to the diffusion of excess free volume biopolymer matrix caused by residual free CA which may act as a plasticizer. Indeed, by decreasing intermolecular attractions between adjacent polymeric chains, plasticizers facilitates the movement of polymer chains under stress (De Souza et al., 2009), resulting in an increase in elongation and a decrease in tensile strength with increasing CA content, already observed by Chabrat et al. (2012). Therefore, during injection-molding, the resulting decrease in viscosity leads to the formation of film samples with higher densities.

\subsection{Influence of citric acid content on the water vapor permeability (WVP), solubility coefficient $(\beta)$, effective diffusion coefficient $\left(D_{\text {eff }}\right)$ and oxygen permeability}

It's important to note that a change in absorption of water occurs as soon as two parts of citric acid were added to the blend (Fig. 2). The reduction in moisture uptake with increasing CA content was more pronounced when $a_{w}<0.6$. In the water activity range $0.6<a_{w}<0.9$, the decrease was smaller and the moisture uptake was increasing rapidly in function of $a_{w}$ which may be related to the water clustering phenomenon (Müller et al., 2009; Zeppa et al., 2009). As described by Zeppa et al. (2009), this phenomenon was favored by the enhanced mobility of the polymer chains in the presence of plasticizer on one hand and to the hydrophilic and hygroscopic plasticizer such as glycerol on the other. Moreover, in such a model proposed by Godbillot et al. (2006), the interaction sites on starch would theoretically be filled with plasticized and water molecules so that additional water is mainly absorbed into the plasticizer-rich phase.

As shown in Fig. 2, the decrease in the moisture content of CA10 which was more pronounced in the water activity range $0.15<a_{w}<0.45$ could be attributed to a decrease in the concentration of polar available sites in the presence of plasticizer and CA (Mali et al., 2005; Zeppa et al., 2009). As a second point, it has been reported that monolayer coverage is reached to a ratio between starch and CA of about 8 to 1 (CA10) (Olsson et al., 2013). At this ratio, citric acid may act as cross-linking agent and reinforces the intermolecular binding of starch macromolecules by forming strong hydrogen bond interaction with starch as to improve the water resistance (Krumova et al., 2000; Park et al., 2005; Reddy and Yang, 2010). Therefore, crosslinking interconnects the starch molecules in the film and provides better intermolecular interaction between molecules leading to a decreasing of water uptake. Nevertheless, when the CA content of the films reached 20 parts, the water uptake was slightly increased. This might be attributed to the plasticization and/or hydrolysis effect of CA and the increase in the plasticizer-rich region with increasing of CA more than 10 parts.

The behavior of the solubility coefficient of water $\beta$ for different citric acid content of films as a function in water activity is shown in Fig. 3. In the water activity range $0<a_{w}<0.6, \beta$ was practically constant but increased very quickly with the water activity increase when $a_{w}>0.6$. This is in agreement with results already observed for starch based materials (Cova et al., 2010; Müller et al., 2008, 2009). 


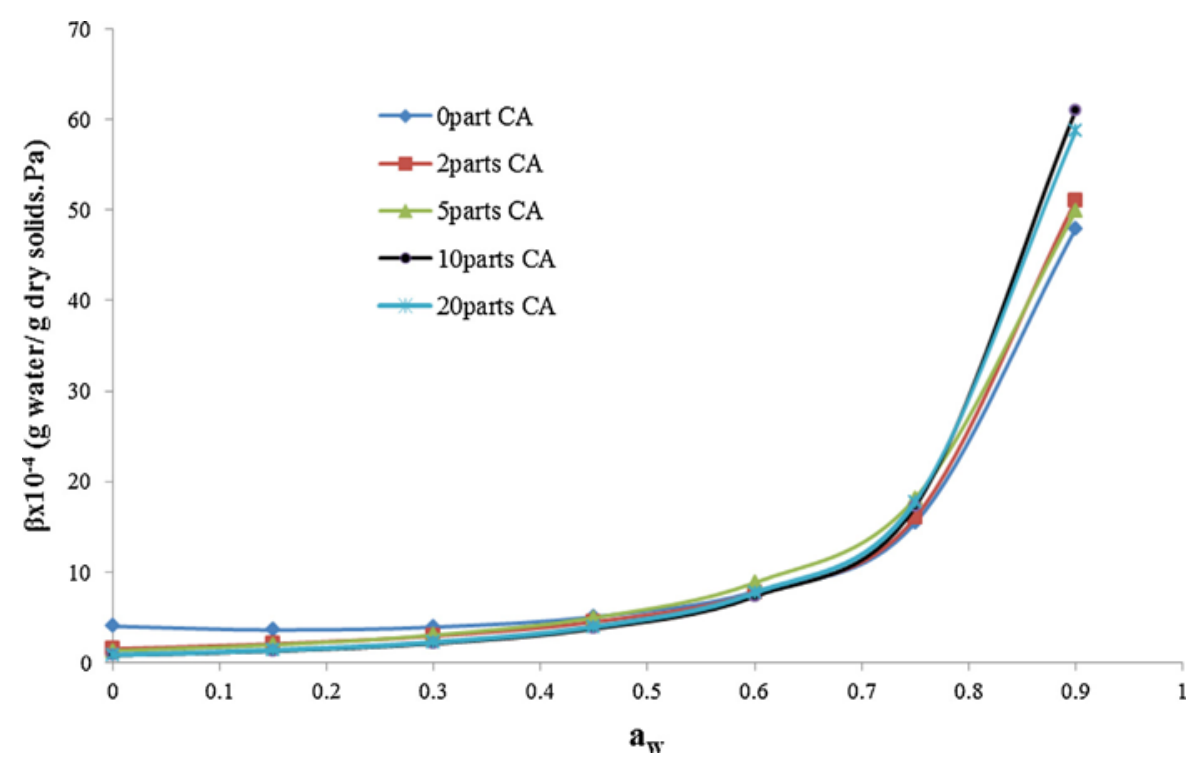

Fig. 3. Solubility coefficient values for different blends as a function of $a_{w}$.

The high water resistance observed in the WVP values when increasing citric acid content from 2 to 10 parts could be assigned to the following reasons. First of all, according to SEM images, when increasing CA ratio to 5 and 10 parts, blends morphology was completely different than blends without CA due to the better PLA distribution (Chabrat et al., 2012). Thus, with improving the dispersion of PLA in the plasticized wheat flour, the diffusion and sorption time of water molecule was significantly increased due to the decreasing of interfacial tension, improving the compatibility between the starch-based matrix and PLA. On the other, as seen with DMTA analyses, damping factor intensity, which magnitude is related to the magnitude of storage modulus drop and depends of the number of mobile entities participating to the relaxation process, seemed to be weaker for small amounts of citric acid (CA2 and CA5) (Chabrat et al., 2012). This phenomenon can be attributed to the less chains mobility and hence reduced the free volume resulting of improved the intermolecular interaction of the blends.

The increasing in the WVP value for CA20 might be caused by two reasons. The first is the plasticization effect of CA as was previously mentioned. Indeed, as seen with DMTA analyses, damping factor intensity was higher for CA20, meaning an increasing mobility and formation spaces between the macromolecular chains which in turn promotes water vapor diffusivity through the films. This is in agreement with papers already published (Ghanbarzadeh et al., 2011; Ma et al., 2009). The second cause is that CA can promote the hydrolysis of the starch glycosidic bonds leading to shorter molecules having more mobility. Moreover, as already reported in the first part of this study (Chabrat et al., 2012), the extrusion parameters (specific mechanical energy, matter temperature in the plasticization zone and die pressure) significantly decreased. This might be attributed to the decrease of blends viscosity which indicates that starch and PLA were hydrolysed (Hirashima et al., 2004; Shi et al., 2007).

In order to understand the mechanisms governing the permeation process of water vapor through films, the variation of $D_{\text {eff }}$, $\beta$ and WVP values were plotted as a function in CA content. The effective diffusion coefficient $D_{\text {eff }}$ calculated from $\beta$ and WVP data for $a_{w}=0.6$ are presented in Table 3. The diffusion coefficient values determined in this study had the same order of magnitude as those reported by Muller et al. (2012) and Yew et al. (2005). It's of interest to notice that the variation of coefficient diffusion values as a function of citric acid content had the same trend as that observed for WVP. These results found in this study showed that WVP was greatly dependent on $D_{\text {eff }}$, since this variation had a great influence on the $D_{\text {eff }}$ values whereas for solubility coefficients values, very little variation with citric acid incorporation was observed.

As oxygen permeability is dependent on film composition, the influence of the amount of CA will be discussed in the following. As shown in Table 4, the incorporation of CA decreased the oxygen permeability whatever CA content. Parameters influencing oxygen permeability are similar to those of water vapor, as previously mentioned. Another explanation is that the citric acid could be viewed as a good compatibilizer between PLA and Wheat flour phases which could fill the holes caused by blending two phases which had not the same chemical nature. Addition of citric acid could then greatly affect the gas transport properties by acting as an obstacle to the motion oxygen molecules through films.

According to all made characterizations in this study (barrier, water sorption properties) and the first paper (mechanical, morphological, thermal properties) (Chabrat et al., 2012), CA2 seems to be the best formulation.

\section{Conclusion}

New environmentally friendly blends, prepared via industrial equipments were characterized to assess their suitability for use as injection-molded packaging material. Citric acid was added to wheat flour/PLA blends to improve the miscibility of PLA and wheat flour and evaluate its effect on their barrier properties.

The tendency of film densities as a function in the WVP and oxygen permeability was different from that observed for conventional plastics. The presence of low citric acid content (10 parts of CA) significantly reduced the WVP up to $80 \%$ and around $90 \%$ the oxygen permeability. It was shown that this effect was linked to a better dispersion of PLA. The results found for water sorption isotherms showed that films' water vapour permeability have strong dependency on water diffusion coefficients $\left(D_{\text {eff }}\right)$. Adding too much citric acid led to a plasticization and/or hydrolysis effect of wheat flour/PLA blends thus involving a decrease in the WVP of these blends.

For future works, blending thermoplastic wheat flour with another biopolymer such as polyhydroxybutyrate (PHB) and citric acid would be very interesting. 


\section{Acknowledgements}

The authors gratefully acknowledge Guadalupe Vaca Medina for her help for water sorption analyses and the FUI (Fonds Unique Interministeriels) for the financial support.

\section{References}

Almenar, E., Auras, R., 2010. Permeation, sorption, and diffusion in poly(lactic acid). In: Auras, R., Lim, L.-T., Selke, S.E.M., Tsuji, H. (Eds.), Poly(Lactic Acid). John Wiley \& Sons, Inc., Hoboken, NJ, USA, pp. 155-179.

Angellier, H., Molina-Boisseau, S., Dole, P., Dufresne, A., 2006. Thermoplastic starch-waxy maize starch nanocrystals nanocomposites. Biomacromolecules 7 , 531-539.

Auras, R.A., Singh, S.P., Singh, J.J., 2005. Evaluation of oriented poly(lactide) polymers vs. existing PET and oriented PS for fresh food service containers. Packag. Technol. Sci. 18, 207-216.

Buléon, A., Colonna, P., Planchot, V., Ball, S., 1998. Starch granules: structure and biosynthesis. Int. J. Biol. Macromol. 23, 85-112.

C16 Committee, 2010. Test Methods for Water Vapor Transmission of Materials (ASTM International).

Chabrat, E., Abdillahi, H., Rouilly, A., Rigal, L., 2012. Influence of citric acid and water on thermoplastic wheat flour/poly(lactic acid) blends. I: thermal, mechanical and morphological properties. Ind. Crops Prod. 37, 238-246.

Chanvrier, H., Uthayakumaran, S., Lillford, P., 2007. Rheological properties of wheat flour processed at low levels of hydration: influence of starch and gluten. J. Cereal Sci. $45,263-274$

Le Corre, D., Bras, J., Dufresne, A., 2010. Starch nanoparticles: a review. Biomacromolecules 11, 1139-1153.

Cova, A., Sandoval, A.J., Balsamo, V., Müller, A.J., 2010. The effect of hydrophobic modifications on the adsorption isotherms of cassava starch. Carbohydr. Polym. $81,660-667$

Forssell, P.M., Mikkilä, J.M., Moates, G.K., Parker, R., 1997. Phase and glass transition behaviour of concentrated barley starch-glycerol-water mixtures, a model for thermoplastic starch. Carbohydr. Polym. 34, 275-282.

Ghanbarzadeh, B., Almasi, H., Entezami, A.A., 2011. Improving the barrier and mechanical properties of corn starch-based edible films: effect of citric acid and carboxymethyl cellulose. Ind. Crops Prod. 33, 229-235.

Ghiasi, K., Hoseney, R.C., Varriano-Marston, E., 1982. Effects of flour components and dough ingredients on starch gelatinization. Packagi. Technol. Sci. 60 , $58-61$

Godbillot, L., Dole, P., Joly, C., Rogé, B., Mathlouthi, M., 2006. Analysis of water binding in starch plasticized films. Food Chem. 96, 380-386.

Gómez-Martínez, D., Partal, P., Martínez, I., Gallegos, C., 2009. Rheological behaviour and physical properties of controlled-release gluten-based bioplastics. Bioresour. Technol. 100, 1828-1832.

Gontard, N., Duchez, C., Cuq, J., Guilbert, S., 1994. Edible composite films of wheat gluten and lipids: water vapour permeability and other physical properties. Int. J. Food Sci. Technol. 29, 39-50.

Hirashima, M., Takahashi, R., Nishinari, K., 2004. Effects of citric acid on the viscoelasticity of cornstarch pastes. J. Agric. Food Chem. 52, 2929-2933.

Ke, T. Sun, X., 2001. Thermal and mechanical properties of poly(lactic acid) and starch blends with various plasticizers. Trans. ASAE 44, 945-953.

Krumova, M., López, D., Benavente, R., Mijangos, C., Pereña, J., 2000. Effect of crosslinking on the mechanical and thermal properties of poly(vinyl alcohol). Polymer 41, 9265-9272.

Labrecque, L.V., Kumar, R.A. Davé, V. Gross, R.A., McCarthy, S.P. 1997. Citrate esters as plasticizers for poly(lactic acid). J. Appl. Polym. Sci. 66, 1507-1513.

Larotonda, F.D.S., Matsui, K.N., Sobral, P.J.A., Laurindo, J.B., 2005. Hygroscopicity and water vapor permeability of Kraft paper impregnated with starch acetate. J. Food Eng. 71, 394-402.

Leblanc, N., Saiah, R., Beucher, E., Gattin, R., Castandet, M., Saiter, J.-M., 2008. Structural investigation and thermal stability of new extruded wheat flour based polymeric materials. Carbohydr. Polym. 73, 548-557.

Liu, Z.Q., Yi, X.-S., Feng, Y., 2001. Effects of glycerin and glycerol monostearate on performance of thermoplastic starch. J. Mater. Sci. 36, 1809-1815.

Ma, X., Jian, R., Chang, P.R., Yu, J., 2008. Fabrication and characterization of citric acid-modified starch nanoparticles/plasticized-starch composites. Biomacromolecules 9, 3314-3320.
Ma, X., Chang, P.R., Yu, J., Stumborg, M., 2009. Properties of biodegradable citric acid-modified granular starch/thermoplastic pea starch composites. Carbohydr. Polym. 75, 1-8.

Mali, S., Sakanaka, LS. Yamashita, F. Grossmann, M.V., 2005. Water sorption and mechanical properties of cassava starch films and their relation to plasticizing effect. Carbohydr. Polym. 60, 283-289.

Maria Martelli, S., Moore, G., Silva Paes, S., Gandolfo, C., Laurindo, J.B., 2006. Influence of plasticizers on the water sorption isotherms and water vapor permeability of chicken feather keratin films. Lwt - Food Sci. Technol. 39, 292-301.

Martin, O., Avérous, L., 2001. Poly(lactic acid): plasticization and properties of biodegradable multiphase systems. Polymer 42, 6209-6219.

Meares, P., 1954. The diffusion of gases through polyvinyl acetate. J. Am. Chem. Soc. 76, 3415-3422.

Miller, K.S., Krochta, J.M., 1997. Oxygen and aroma barrier properties of edible films: a review. Trends Food Sci. Technol. 8, 228-237.

Muller, C.M.O., Pires, A.T.N., Yamashita, F., 2012. Characterization of thermoplastic starch/poly(lactic acid) blends obtained by extrusion and thermopressing. J. Braz. Chem. Soc. 23, 426-434.

Müller, C.M.O.,Yamashita, F., Laurindo, J.B., 2008. Evaluation of the effects of glycerol and sorbitol concentration and water activity on the water barrier properties of cassava starch films through a solubility approach. Carbohydr. Polym. 72, 82-87.

Müller, C.M.O., Laurindo, J.B., Yamashita, F., 2009. Effect of cellulose fibers addition on the mechanical properties and water vapor barrier of starch-based films. Food Hydrocolloids 23, 1328-1333.

Olsson, E., Hedenqvist, M.S., Johansson, C., Järnström, L., 2013. Influence of citric acid and curing on moisture sorption, diffusion and permeability of starch films. Carbohydr. Polym. 94, 765-772.

Park, H.-R. Chough, S.-H., Yun, Y.-H., Yoon, S.-D., 2005. Properties of starch/PVA blend films containing citric acid as additive. J. Polym. Environ. 13, 375-382.

Petersen, K., Væggemose Nielsen, P., Bertelsen, G., Lawther, M., Olsen, M.B., Nilsson, N.H., Mortensen, G., 1999. Potential of biobased materials for food packaging. Trends Food Sci. Technol. 10, 52-68.

Petersen, K., Nielsen, P.V., Olsen, M.B., 2001. Physical and mechanical properties of biobased materials starch, polylactate and polyhydroxybutyrate. Starch/Stärke 53,356

Reddy, N., Yang, Y., 2010. Citric acid cross-linking of starch films. Food Chem. 118, 702-711.

Rocha Plácido Moore, G., Maria Martelli, S., Gandolfo, C., José do Amaral Sobral, P., Borges Laurindo, J., 2006. Influence of the glycerol concentration on some physical properties of feather keratin films. Food Hydrocolloids 20, 975-982.

Roman-Gutierrez, A.D. Guilbert, S., Cuq, B., 2002 Distribution of water between wheat flour components: a dynamic water vapour adsorption study. J. Cereal Sci. 36, 347-355.

Shi, R., Zhang, Z., Liu, Q., Han, Y., Zhang, L., Chen, D., Tian, W., 2007. Characterization of citric acid/glycerol co-plasticized thermoplastic starch prepared by melt blending. Carbohydr. Polym. 69, 748-755.

Shishatskii, A.M., Yampol'skii, Y.P., Peinemann, K.-V., 1996. Effects of film thickness on density and gas permeation parameters of glassy polymers. J. Membr. Sci. $112,275-285$.

Sothornvit, R., Krochta, J.M., 2001. Plasticizer effect on mechanical properties of $\beta$ lactoglobulin films. J. Food Eng. 50, 149-155

De Souza, A.C., Ditchfield, C., Tadini, C., 2009. Biodegradable films based on biopolymers for food industries. In: Passos, M., Ribeiro, C. (Eds.), Innovation in Food Engineering. CRC Press, Sao Paulo, Brazil, pp. 511-537.

Thiebaud, S., Aburto, J., Alric, I., Borredon, E., Bikiaris, D., Prinos, J., Panayiotou, C., 1997. Properties of fatty-acid esters of starch and their blends with LDPE. J. Appl. Polym. Sci. 65, 705-721.

Wonders, A.G., Paul, D.R., 1979. Effect of $\mathrm{CO}_{2}$ exposure history on sorption and transport in polycarbonate. J. Membr. Sci. 5, 63-75.

Xie, X. (Sherry), Liu, Q., 2004. Development and physicochemical characterization of new resistant citrate starch from different corn starches. Starch - Stärke 56 364-370.

Yew, G.H., Mohd Yusof, A.M., Mohd Ishak, Z.A., Ishiaku, U.S., 2005. Water absorption and enzymatic degradation of poly(lactic acid)/rice starch composites. Polym. Degrad. Stabil. 90, 488-500.

Yew, G.H., Chow, W.S., Ishak, Z.A.M., Yusof, A.M.M., 2009. Natural weathering of poly(lactic acid): effects of rice starch and epoxidized natural rubber. J. Elast. Plast. 41, 369-382.

Zeppa, C. Gouanvé, F., Espuche, E., 2009. Effect of a plasticizer on the structure of biodegradable starch/clay nanocomposites: thermal, water-sorption, and oxygen-barrier properties. J. Appl. Polym. Sci. 112, 2044-2056. 